\title{
Insulin therapy is not associated with improved clinical outcomes in critically ill infants with stress hyperglycemia
}

\author{
FANG WEN $^{1 *}$, YI ZHANG $^{2 *}$, CHUNWANG LIN $^{1}$, MINGHONG DENG $^{1}$, JINFENG ZHANG ${ }^{1}$ and JIANPING ZHANG $^{1}$ \\ ${ }^{1}$ Pediatric Intensive Care Unit, The Shunde Women's and Children's Healthcare Hospital, \\ Foshan, Guangdong 528300; ${ }^{2}$ Pediatric Intensive Care Unit, The Yuexiu District Children's \\ Hospital of Guangzhou, Guangzhou, Guangdong 510462, P.R. China
}

Received July 25, 2018; Accepted April 16, 2019

DOI: $10.3892 /$ etm.2019.7537

\begin{abstract}
The aim of the present study was to examine the benefits of insulin use and non-use in critically ill infants with stress-induced hyperglycemia. The present retrospective study used clinical data from 302 critically ill infants with stress hyperglycemia admitted to pediatric intensive care units (PICUs). The patients were recruited randomly and divided into three groups: The tight glycemic control, conventional insulin therapy and control groups. Correlations between insulin therapy and improved clinical outcomes were assessed according to key parameters (length of PICU stay, total length of stay, occurrence of organ dysfunction and mortality). Correlations between blood glucose level and these parameters in the three groups were also examined. Blood glucose levels following insulin therapy were not correlated with the length of PICU stay, total length of stay, mortality, secondary coma, or secondary hepatic or renal dysfunction in the three groups. At $96 \mathrm{~h}$ following PICU admission, blood glucose levels were statistically similar $(5.0 \pm 1.2,4.9 \pm 1.3$ and $5.1 \pm 0.9 \mathrm{mmol} / \mathrm{l}$, respectively; $\mathrm{P}>0.05)$. Insulin therapy was revealed to have no benefit on the length of hospitalization, the occurrence of organ dysfunction or mortality in critically ill pediatric patients with stress hyperglycemia. Even with no insulin use, the blood glucose level could spontaneously return to normal, with no associated risk of organ dysfunction or fatality.
\end{abstract}

\section{Introduction}

Critically ill patients typically have high blood glucose levels, which is a stress indicator for patients with no history

Correspondence to: Dr Fang Wen, Pediatric Intensive Care Unit, The Shunde Women's and Children's Healthcare Hospital, 3 Baojian Street, Shunde, Foshan, Guangdong 528300, P.R. China

E-mail: 782890403@qq.com

${ }^{*}$ Contributed equally

Key words: stress hyperglycemia, critically ill, insulin therapy, insulin non-use, benefit, infants of diabetes (1-6). High blood glucose levels need to be controlled (2,7-13). Various studies have demonstrated that tight glycemic control (TGC) can reduce the risk of mortality and complications, as well as have other benefits. Tran et al (14) and Pham et al (15) reported that TGC is necessary in children with severe burns. A prospective randomized trial revealed that it can reduce the risk of mortality in patients with sepsis (5). Vlasselaers et al (16) indicated that intraoperative TGC can protect the myocardium and reduce infection in neonatal patients with severe heart disease. Furthermore, Day et al (17) revealed that TGC benefits critically ill pediatric patients with meningococcal sepsis. In addition, a study conducted at Leuven University in Belgium indicated that intensive insulin therapy (i.e., TGC) can reduce mortality in critically ill adult and pediatric patients $(9,18)$. However, the optimal blood glucose control target for critically ill children remains uncertain, and some researchers have questioned proposed glucose control targets and, more generally, the benefit of TGC (19-21). In the present study, the characteristics of pediatric patients at first admission were examined, and the effects of blood glucose control [TGC, conventional insulin therapy (CIT) and no insulin] were analyzed using data from critically ill children. The length of stay in the pediatric intensive care unit (PICU), total length of hospitalization, mortality, occurrence of secondary coma, development of secondary hepatic or renal dysfunction, incidence of hypoglycemia and blood glucose reduction were compared among groups. Furthermore, correlations between blood glucose levels and mortality, secondary coma, and secondary hepatic and renal dysfunction following insulin therapy were examined. Blood glucose levels were observed at the time of PICU admission and 24, 48, 72 and $96 \mathrm{~h}$ thereafter in the TGC, CIT and control groups. Overall, the benefits of blood glucose control and non-use of insulin therapy were evaluated and the spontaneous resolution of the blood glucose level without insulin therapy was assessed. The study findings suggested that the blood glucose level could return to normal spontaneously, without insulin therapy and with no associated risk, in critically ill pediatric patients with stress hyperglycemia.

\section{Materials and methods}

Ethics and written informed consent. The Ethics Committee of the Shunde Women's and Children's Healthcare Hospital 
(Foshan, China) approved the present study. Prior to the start of the research, written informed consent was obtained from next of kin, carers and/or guardians on behalf of the children enrolled in the study.

Study population. All subjects included in the present study were admitted to the Shunde Women's and Children's Healthcare Hospital and Yuexiu District Children's Hospital of Guangzhou between June 2009 and June 2017. Clinical data was collected from 302 critically ill infants with hyperglycemia who were admitted to the hospitals' PICUs. The following data were extracted from patient medical records: Patient age (range, 1-12 months), sex (male, $n=156$; femal, $n=146$ ), diagnosis (22), history of diabetes, steroid use, nutrition delivery, SOFA-associated indicators, length of PICU stay, total length of hospitalization, mortality, occurrence of secondary coma, development of secondary hepatic and renal dysfunction, incidence of ketoacidosis, blood glucose level at PICU admission and change in blood glucose level (at 24, 48, 72 and $96 \mathrm{~h}$ ), blood ketone level, urine ketone response and blood $\mathrm{pH}$ values at first admission and at 24, 48, 72 and 96 h, Eligible subjects met the following criteria: i) Critically ill infants (aged, 1 to 12 months) with stress hyperglycemia; ii) patients examined had with no past history of diabetes (considering both parents); and iii) patients examined had recorded steroid use prior to recruitment.

Patient evaluation. Sepsis and septic shock were evaluated using the Sequential (Sepsis-Related) Organ Failure Assessment (SOFA) and defined according to the Third International Consensus Definitions for Sepsis and Septic Shock (Sepsis-3) (23). Stress hyperglycemia was defined according to the American Diabetes Association's Diabetes in Hospitals Writing Committee Guidelines (fasting blood glucose $\geq 7.0 \mathrm{mmol} / 1$ or random blood glucose $\geq 11.1 \mathrm{mmol} / \mathrm{l}$ ) (22). Severe hyperglycemia was defined as a blood glucose level $\geq 25.00 \mathrm{mmol} / \mathrm{l}$ at first admission (22). Secondary coma, secondary hepatic dysfunction and secondary renal dysfunction in patients with sepsis were defined according to the Sepsis-3 (23). Secondary coma was defined as a Glasgow score $<8$ following hospitalization; secondary hepatic dysfunction was defined as a total bilirubin level $>4 \mathrm{mg} / \mathrm{dl}(72 \mathrm{mmol} / \mathrm{l})$ or alanine aminotransferase level of at least two times the upper limit of the normal level for the patient's age; and secondary renal dysfunction was defined as a serum creatinine level of at least two times the upper limit of the normal level for the patient's age or a 2-fold increase in the baseline creatinine level during the PICU stay. Hypoglycemia was defined as a blood glucose level $<2.8 \mathrm{mmol} / 1$, and severe hypoglycemia was defined as a level $\leq 2.2 \mathrm{mmol} / \mathrm{l}$ (24). Ketoacidosis was defined according to the International Society for Pediatric and Adolescent Diabetes biochemical criteria as a blood glucose level $>11 \mathrm{mmol} / 1$ and venous $\mathrm{pH}<7.3$ following hospitalization, and presence of ketonemia and ketonuria $(25,26)$.

Grouping method. The patients were into three groups: TGC ( $\mathrm{n}=85)$, CIT ( $\mathrm{n}=89)$ and control (no insulin use; $\mathrm{n}=128$ ) groups. Blood glucose control points were as follows: $<6.1$ to $4.4 \mathrm{mmol} / \mathrm{l}$ for the TGC group and $10.0 \mathrm{mmol} / \mathrm{l}$ or less per liter $(4,9)$ for the CIT group. Insulin administration was stopped in the two groups when the target range was reached. Patients who did not receive insulin therapy were assigned to the control group.

Insulin therapy and nutritional support treatment. Continuous short-acting insulin infusion was delivered with a micropump. The insulin dose was $0.5-1 \mathrm{IU} / \mathrm{kg} \cdot d a y$, and was adjusted according to the blood glucose level. Blood glucose levels were measured with a bedside glucose meter (Free Style Optium Neo; model XEMV168-026F; Abbott Diabetes Care Ltd., Chicago, IL, USA) every 30 min following insulin adjustment. Enteral nutrition was initiated as early as possible for all patients. Nutrition standards were established according to nutritional support treatment guidelines (27), with total calories set to $20-30 \mathrm{kcal} \cdot \mathrm{kg}^{-1} \cdot 24 \mathrm{~h}^{-1}$ (nitrogen, $0.08-0.25 \mathrm{~g} \cdot \mathrm{kg}^{-1} \cdot 24 \mathrm{~h}^{-1}$; $20-40 \%$ fat emulsion).

Statistical analyses. Statistical analyses were performed with SPSS statistical software (version 17.0; SPSS, Inc., Chicago, IL, USA). Figures were generated using GraphPad software (La Jolla, CA, USA; version 5.01). P<0.05 was considered to indicate a statistically significant difference. Kolmogorov-Smirnov testing was used to investigate the distribution of blood glucose levels in the TGC, CIT and control groups. The results indicated that these distributions were normal $(\mathrm{Z}=0.935, \mathrm{P}=0.080 ; \mathrm{Z}=0.912, \mathrm{P}=0.088$; and $\mathrm{Z}=0.917$, $\mathrm{P}=0.091$, respectively). The $\chi^{2}$ test was used for intergroup comparison of count data (sex, mortality, secondary coma, secondary hepatic dysfunction, secondary renal dysfunction and incidence of hypoglycemia). Age, SOFA score, length of PICU stay, total length of hospitalization, and blood glucose levels at PICU admission and thereafter were presented as the mean \pm standard deviation. Results were compared between multiple groups using one-way ANOVA, while a Neuman-keuls test was applied to compare differences among these groups. Pearson's test was applied to examine correlations between blood glucose levels following insulin therapy and mortality, secondary coma, and secondary hepatic and renal dysfunction in all patients.

\section{Results}

A total of 302 patients (156 male patients and 146 female patients), with a mean age at enrollment of 7 months (range, 1 to 12 months), were assessed in the present study. Patients had the following diseases: Sepsis $(n=67)$, septic shock $(n=23)$, severe pneumonia $(n=120)$, meningoencephalitis $(n=28)$, acute lung hemorrhage $(\mathrm{n}=18)$, acute laryngeal obstruction $(\mathrm{n}=11)$, persistent asthma $(n=10)$, acute myocarditis $(n=11)$, acute nephritis $(n=8)$ and necrotic enteritis $(n=6)$. Among critically ill patients with stress hyperglycemia in the TGC $(\mathrm{n}=85)$, CIT $(n=89)$ and control $(n=128)$ groups, these venous blood glucose levels did not differ significantly between male $(n=156)$ and female patients $(\mathrm{n}=146 ; 14.7 \pm 1.9$ and $14.6 \pm 1.8 \mathrm{mmol} / \mathrm{l}$ respectively; $\mathrm{P}>0.05$; Table I). No patient had severe stress hyperglycemia (blood glucose level $>25.00 \mathrm{mmol} / \mathrm{l}$ ). There was not significant difference in mean venous blood glucose levels at first admission $(15.2 \pm 3.8,14.6 \pm 4.5$ and $14.2 \pm 4.7 \mathrm{~m}$ mol/1, respectively; P $>0.05$; Table II, Fig. 1). Certain characteristics of pediatric patients at first administration did not 
Table I. Blood glucose levels at first admission according to pathology and sex.

\begin{tabular}{|c|c|c|c|c|c|c|}
\hline \multirow[b]{2}{*}{ Factor } & \multicolumn{2}{|r|}{ Total } & \multicolumn{2}{|r|}{ Male } & \multicolumn{2}{|r|}{ Female } \\
\hline & $\mathrm{n}$ & Blood glucose (mmol/l) & $\mathrm{n}$ & Blood glucose (mmol/l) & $\mathrm{n}$ & Blood glucose (mmol/l) \\
\hline \multicolumn{7}{|l|}{ Disease } \\
\hline Sepsis & 67 & $15.0 \pm 1.6$ & 35 & $15.1 \pm 1.1$ & 32 & $14.8 \pm 2.1$ \\
\hline Septic shock & 23 & $16.7 \pm 2.0$ & 12 & $16.8 \pm 2.0$ & 11 & $16.5 \pm 1.9$ \\
\hline Severe pneumonia & 120 & $14.7 \pm 1.5$ & 62 & $14.6 \pm 1.2$ & 58 & $14.8 \pm 1.7$ \\
\hline Meningoencephalitis & 28 & $14.1 \pm 1.8$ & 13 & $14.1 \pm 1.5$ & 15 & $14.0 \pm 2.1$ \\
\hline Acute lung hemorrhage & 18 & $15.0 \pm 1.4$ & 10 & $15.1 \pm 1.1$ & 8 & $14.8 \pm 1.7$ \\
\hline Acute laryngeal obstruction & 11 & $14.5 \pm 1.5$ & 6 & $14.8 \pm 1.3$ & 5 & $14.1 \pm 1.7$ \\
\hline Persistent asthma & 10 & $13.1 \pm 1.6$ & 6 & $13.0 \pm 1.5$ & 4 & $13.1 \pm 1.7$ \\
\hline Acute myocarditis & 11 & $13.4 \pm 1.9$ & 5 & $12.7 \pm 2.3$ & 6 & $14.0 \pm 1.5$ \\
\hline Acute nephritis & 8 & $12.6 \pm 1.5$ & 4 & $12.5 \pm 1.4$ & 4 & $12.7 \pm 1.6$ \\
\hline Necrotic enteritis & 6 & $13.6 \pm 1.6$ & 3 & $13.1 \pm 2.1$ & 3 & $14.0 \pm 1.1$ \\
\hline Disease total & 302 & & 156 & $14.7 \pm 1.9$ & 146 & $14.6 \pm 1.8$ \\
\hline
\end{tabular}

Total male vs. female: $\chi^{2}=1.23, \mathrm{P}=0.71$; total blood glucose: $\mathrm{F}=0.3, \mathrm{P}=0.68$.

Table II. Characteristics of patients at first admission.

\begin{tabular}{|c|c|c|c|c|}
\hline Variable & TGC group & CIT group & Control group & P-value \\
\hline Number of subjects & 85 & 89 & 128 & - \\
\hline Age (months) & $7 \pm 4.9$ & $7 \pm 4.5$ & $7 \pm 4.6$ & 0.22 \\
\hline Male $(\%)$ & 51.66 & 52.54 & 51.44 & 0.71 \\
\hline Blood glucose, mmol/1 & $15.2 \pm 3.8$ & $14.6 \pm 4.5$ & $14.2 \pm 4.7$ & $0.66^{\mathrm{a}}, 0.69^{\mathrm{b}}$ and $0.67^{\mathrm{c}}$ \\
\hline Arterial oxygen saturation, $\%$ & $81 \pm 11.5$ & $80 \pm 21.4$ & $82 \pm 20.1$ & 0.29 \\
\hline $\mathrm{PaO}_{2} / \mathrm{FI} \mathrm{O}_{2}, \mathrm{kPa}$ & $28.7 \pm 15.7$ & $30.5 \pm 14.3$ & $29.6 \pm 12.7$ & 0.30 \\
\hline Systolic blood pressure, $\mathrm{mmHg}$ & $71 \pm 15.2$ & $70 \pm 86.4$ & $73 \pm 35.6$ & 0.19 \\
\hline MAP, mm Hg & $51 \pm 18.2$ & $53 \pm 11.5$ & $51 \pm 17.7$ & 0.32 \\
\hline $\mathrm{pH}$ value & $7.2 \pm 0.2$ & $7.2 \pm 0.5$ & $7.2 \pm 0.4$ & 0.59 \\
\hline Hemoglobin, g/l & $87 \pm 17$ & $89 \pm 35$ & $89 \pm 24$ & 0.26 \\
\hline Platelet, $10 \times 10^{9} / 1$ & $9.1 \pm 0.7$ & $9.0 \pm 0.3$ & $9.0 \pm 0.6$ & 0.32 \\
\hline Total bilirubin, $\mu \mathrm{mol} / 1$ & $19 \pm 8.7$ & $18 \pm 9.4$ & $19 \pm 11.8$ & 0.25 \\
\hline ALT, U/1 & $39 \pm 19$ & $37 \pm 15$ & $37 \pm 2$ & 0.27 \\
\hline Creatinine, mg/dl & $1.1 \pm 0.8$ & $1.0 \pm 0.7$ & $1.0 \pm 0.5$ & 0.30 \\
\hline C-reactive protein, mg/l & $49 \pm 22.7$ & $47 \pm 19.0$ & $47 \pm 27.4$ & 0.26 \\
\hline Procalcitonin, mg/l & $3 \pm 1.1$ & $3 \pm 1.4$ & $3 \pm 1.3$ & 0.49 \\
\hline Blood lactic acid, mmol/1 & $3 \pm 0.9$ & $3 \pm 1.1$ & $3 \pm 1.2$ & 0.53 \\
\hline Urine volume, $\mathrm{ml} / \mathrm{kg} \cdot \mathrm{h} \cdot$ & $0.6 \pm 0.3$ & $0.6 \pm 0.1$ & $0.6 \pm 0.3$ & 0.97 \\
\hline GCS, score & $10 \pm 2.2$ & $10 \pm 2.7$ & $10 \pm 2.6$ & 0.54 \\
\hline SOFA, score & $8.67 \pm 3.14$ & $8.79 \pm 2.55$ & $8.80 \pm 2.61$ & 0.28 \\
\hline
\end{tabular}

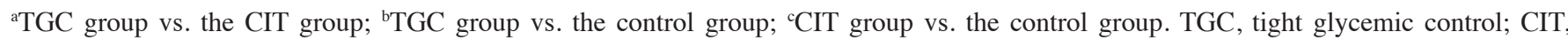
conventional insulin therapy; $\mathrm{PaO}_{2} / \mathrm{FiO}_{2}$, oxygenation index; MAP, mean arterial pressure; ALT, alanine aminotransferase; GCS, Glasgow Coma Scale; SOFA, Sequential (Sepsis-Related) Organ Failure Assessment.

differ among groups (Table II), including age, male sex, blood glucose, arterial oxygen saturation, $\mathrm{PaO} 2$ /FI O2, systolic blood pressure and MAP.

Length of PICU stay and total length of hospitalization were shorter in the TGC group when compared with the CIT and control groups; however this difference was not significant ( $P>0.05)$. Mortality and the occurrence of secondary coma, secondary hepatic dysfunction and secondary renal dysfunction did not significantly differ among groups $(\mathrm{P}>0.05)$. At 24, 48 and $72 \mathrm{~h}$, blood glucose levels in TGC, CIT and 


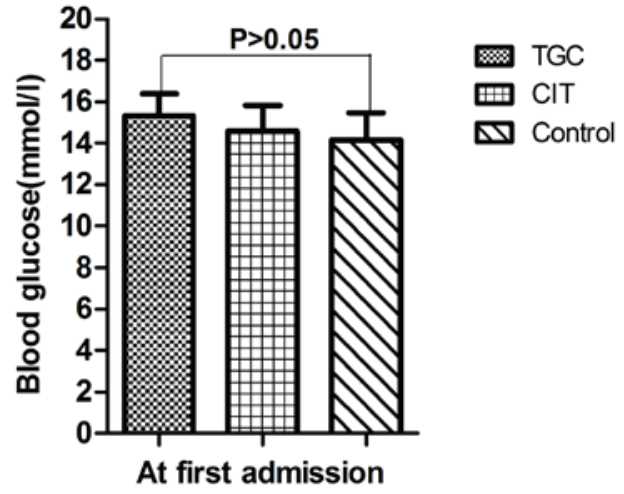

Figure 1. At first admission, blood glucose levels in the TGC, CIT and control groups were $15.2 \pm 3.8,14.6 \pm 4.5$, and $14.2 \pm 4.7 \mathrm{mmol} / \mathrm{l}$, respectively. The differences were not significant $(\mathrm{P}>0.05)$. TGC, tight glycemic control; CIT, conventional insulin therapy.
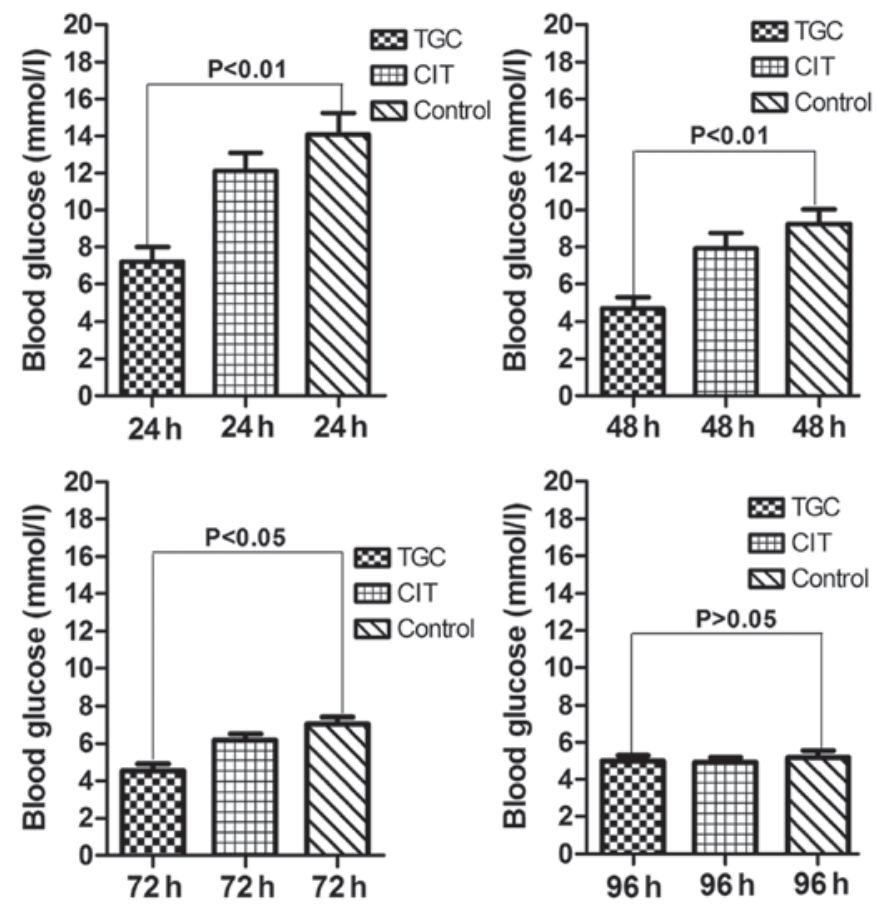

Figure 2. At 24 and $48 \mathrm{~h}$ following admission, blood glucose levels in the TGC, CIT and control groups were 7.4 $\pm 2.5,11.2 \pm 3.8$, and $14.5 \pm 4.1 \mathrm{mmol} / 1$ $(\mathrm{P}=0.007, \mathrm{P}<0.01)$ and $4.8 \pm 2.6,7.9 \pm 2.5$ and $9.5 \pm 3.5 \mathrm{mmol} / 1(\mathrm{P}=0.008$ $\mathrm{P}<0.01)$, respectively; these levels at 72 and $96 \mathrm{~h}$ were $4.7 \pm 1.5,6.3 \pm 1.1$ and $6.8 \pm 1.7 \mathrm{mmol} / 1(\mathrm{P}=0.039, \mathrm{P}<0.05)$ and $5.0 \pm 1.2,4.9 \pm 1.3$ and $5.1 \pm 0.9 \mathrm{mmol} / 1(\mathrm{P}>0.05)$, respectively. TGC, tight glycemic control; CIT, conventional insulin therapy.

control groups differed significantly $[7.4 \pm 2.5,11.2 \pm 3.8$ and $14.5 \pm 4.1 \mathrm{mmol} / 1(\mathrm{P}<0.01) ; 4.8 \pm 2.6,7.9 \pm 2.5$ and $9.5 \pm 3$. $5 \mathrm{mmol} / \mathrm{l}(\mathrm{P}<0.01)$; and $4.7 \pm 1.5,6.3 \pm 1.1$ and $6.8 \pm 1.7 \mathrm{mmol} / 1$ $(\mathrm{P}<0.05)$, respectively]. No significant difference between groups was noted at $96 \mathrm{~h}(5.0 \pm 1.2,4.9 \pm 1.3$, and $5.1 \pm 0.9 \mathrm{mmol} / \mathrm{l}$, respectively; $\mathrm{P}>0.05$; Fig. 2).

Notably, 5 patients in the TGC group exhibited hypoglycemia [blood glucose range, 2.6-2.10 mmol/1: 2.3, 2.6 and $2.7 \mathrm{mmol} / \mathrm{l}$ in 3 (3.53\%) patients; and severe hypoglycemia $(2.10$ and $2.15 \mathrm{mmol} / \mathrm{l})$ in $2(2.35 \%)$ patients] following $26,29,38,43$ and $47 \mathrm{~h}$ of insulin therapy, respectively. The incidence of hypoglycemia was $5.88 \%$. No patient in the CIT or control group exhibited hypoglycemia. Comparison of the incidence of hypoglycemia between multiple groups was significantly different $\left(\chi^{2}=15.62 \mathrm{P}<0.01\right.$; Table III). During the entire administration period, blood glucose levels were not correlated with mortality, secondary coma, hepatic dysfunction or renal dysfunction (Table IV).

Ketone was not detected upon exhaled breath in patients, and blood ketosis and urine ketone response results were negative. At first admission and at 24, 48, 72 and $96 \mathrm{~h}, \mathrm{pH}$ values in the TGC, CIT and control groups did not differ significantly $(\mathrm{P}>0.05$; Table V).

\section{Discussion}

Stress hyperglycemia and insulin resistance are common in critically ill patients, particularly those with sepsis $(3,28)$. Multiple pathogenetic mechanisms are responsible for this metabolic syndrome; however, increased release of pro-inflammatory mediators and counter-regulatory hormones may serve a pivotal role (28). This process leads to accelerated catabolism and strengthened dysplasia function of glucose, which in turn results in stress hyperglycemia (28). This condition is caused by a decrease in insulin secretion under stress and represents a temporary state of insulin resistance and concomitant relative insulin deficiency (3-6). In early studies, Van den Berghe et al (9) proposed the use of insulin therapy for TGC (blood glucose level $<6.1 \mathrm{mmol} / \mathrm{l}$ ) to reduce mortality and complications in critically ill patients in surgical ICUs. Reports have indicated that this application of insulin therapy can shorten the PICU stay and reduce the mortality, infection and organ dysfunction rates in critically ill patients with stress hyperglycemia $(5,9,13,15-17,29,30)$. However, other studies have documented advantages of freestyle glycemic control using insulin $(24,31)$. The use of TGC is controversial. For example, a study conducted at Leuven University demonstrated beneficial responses to TGC (9), but follow-up studies could not confirm these results $(18,20,21,32)$. Furthermore, a systematic review and network meta-analysis of randomized controlled trials revealed no benefit of TGC with regard to the length of hospitalization or death in critically ill patients (8). The persisting disparities in results reflect the difficulty of replicating such research.

Severe stress hyperglycemia (blood glucose level $>25.00 \mathrm{mmol} / \mathrm{l})$ was observed in no patients $(0.00 \%)$ in the present sample; $100 \%$ of patients had mild to moderate stress hyperglycemia. This high blood glucose state seems to cause limited harm to the body, but information on this issue is limited. In the present study, no significant difference in the length of PICU stay or total length of hospitalization among the TGC, CIT and control groups was indicated. In addition, no correlation between the blood glucose level and mortality, occurrence of secondary coma, or development of secondary hepatic dysfunction and renal dysfunction was indicated following treatment. These findings suggest no superiority of TGC over other approaches, which is in agreement with previously reported results $(8,20)$. Thus, the present findings did not demonstrate a benefit of insulin therapy or risk associated with its non-use. Although we are not aware of previous reports on the latter, the present retrospective study demonstrated that transient mild to moderate stress hyperglycemia does not typically cause harm and does not necessitate insulin therapy. 
Table III. Comparison of data from the TGC, CIT and control groups.

\begin{tabular}{|c|c|c|c|c|c|c|c|c|}
\hline Variable & $\mathrm{N}$ & $\begin{array}{c}\text { PICU } \\
\text { length of } \\
\text { stay (day) }\end{array}$ & $\begin{array}{c}\text { Total } \\
\text { length of } \\
\text { stay (day) }\end{array}$ & $\begin{array}{c}\text { Mortality } \\
\mathrm{n}(\%)\end{array}$ & $\begin{array}{l}\text { Secondary } \\
\text { coma } \\
\mathrm{n}(\%)\end{array}$ & $\begin{array}{c}\text { Secondary hepatic } \\
\text { dysfunction } \\
\text { n }(\%)\end{array}$ & $\begin{array}{c}\text { Secondary renal } \\
\text { dysfunction } \\
\mathrm{n}(\%)\end{array}$ & $\begin{array}{c}\text { Hypoglycemia } \\
\text { n }(\%)\end{array}$ \\
\hline \multicolumn{9}{|l|}{ Groups } \\
\hline TGC & 85 & $5 \pm 2.4$ & $11 \pm 8.6$ & $10(11.76)$ & $5(5.38)$ & $7(7.53)$ & $6(7.06)$ & $5(5.88)$ \\
\hline CIT & 89 & $5 \pm 8.9$ & $11 \pm 1.2$ & $11(12.36)$ & $5(5.62)$ & $8(7.84)$ & $8(7.84)$ & $0(0.00)$ \\
\hline Control & 128 & $6 \pm 1.8$ & $12 \pm 1.7$ & $15(11.72)$ & $7(5.47)$ & $11(8.59)$ & $9(7.03)$ & $0(0.00)$ \\
\hline$\chi^{2}$ & & 1.16 & 1.27 & 1.25 & 0.83 & 0.97 & 1.04 & 15.62 \\
\hline \multirow[t]{3}{*}{ P-value } & & $>0.05$ & $>0.05$ & $>0.05$ & $>0.05$ & $>0.05$ & $>0.05$ & $<0.01$ \\
\hline & & $\mathrm{P}>0.05$ & $\mathrm{P}>0.05$ & $\mathrm{P}>0.05$ & $\mathrm{P}>0.05$ & $\mathrm{P}>0.05$ & $\mathrm{P}>0.05$ & ${ }^{\mathrm{a}, \mathrm{b}} \mathrm{P}<0.01$ \\
\hline & & & & & & & & ${ }^{\mathrm{c}} \mathrm{P}>0.05$ \\
\hline
\end{tabular}

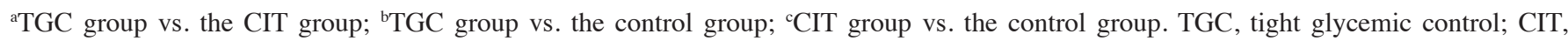
conventional insulin therapy; PICU, pediatric intensive care unit.

Table IV. Correlations of blood glucose levels with correlative factors during the entire administration period in the TGC, CIT and control groups.

\begin{tabular}{lccrrr}
\hline & \multicolumn{2}{c}{ Pearson's test } & \multicolumn{2}{c}{ F test } \\
\cline { 2 - 5 } Correlative factor & $\mathrm{r}$ & P-value & F & P-value \\
\hline Mortality & 0.171 & 0.12 & 19.315 & 0.11 & 0.10 \\
Coma & 0.150 & 0.09 & 17.713 & 0.11 & 0.148 \\
Hepatic dysfunction & 0.166 & 0.10 & 18.431 & 0.12 \\
Renal dysfunction & 0.156 & 0.11 & 19.376 & 0.154 \\
\hline
\end{tabular}

TGC, tight glycemic control; CIT, conventional insulin therapy.

Table V. pH values in the TGC, CIT and control groups.

\begin{tabular}{|c|c|c|c|c|c|}
\hline \multirow[b]{2}{*}{ Groups } & \multicolumn{5}{|c|}{$\mathrm{pH}$ values } \\
\hline & At first & $24 \mathrm{~h}$ & $48 \mathrm{~h}$ & $72 \mathrm{~h}$ & $96 \mathrm{~h}$ \\
\hline \multicolumn{6}{|l|}{ Group } \\
\hline TGC & $7.2 \pm 0.2$ & $7.3 \pm 0.1$ & $7.3 \pm 0.2$ & $7.4 \pm 0.2$ & $7.4 \pm 0.2$ \\
\hline CIT & $7.2 \pm 0.5$ & $7.3 \pm 0.1$ & $7.3 \pm 0.2$ & $7.4 \pm 0.2$ & $7.4 \pm 0.2$ \\
\hline Control & $7.2 \pm 0.4$ & $7.3 \pm 0.2$ & $7.3 \pm 0.1$ & $7.4 \pm 0.1$ & $7.4 \pm 0.1$ \\
\hline $\mathrm{F}$ & 0.29 & 0.32 & 0.29 & 0.29 & 0.29 \\
\hline P-value & $>0.05$ & $>0.05$ & $>0.05$ & $>0.05$ & $>0.05$ \\
\hline
\end{tabular}

TGC, tight glycemic control; CIT, conventional insulin therapy.

The results of the study suggest that the blood glucose level can spontaneously return to normal as the severe inflammatory reaction subsides and the patient's condition improves. Marik and Raghavan (28) indicated that only persistently high blood glucose levels can cause organ damage. In the control group in the present study, blood glucose levels had dropped to $9.5 \pm 3.5 \mathrm{mmol} / \mathrm{l}$ at $48 \mathrm{~h}$ following PICU admission, were $6.8 \pm 1.7 \mathrm{mmol} / \mathrm{l}$ at $72 \mathrm{~h}$, and were considered normal $(5.2 \pm 0.9 \mathrm{mmol} / \mathrm{l})$ at $96 \mathrm{~h}$. However, further investigation is required to confirm these findings.

The present observation of hypoglycemia following therapy in 5 patients in the TGC group (severe in 2 cases) is in agreement with the results of a meta-analysis, which documented an increased risk of hypoglycemia that was associated 
with target blood glucose levels $<110 \mathrm{mg} / \mathrm{dl}$ (6.1 mmol/l) (20). Although no correlation between the blood glucose level and mortality or other complications was identified, the potential risk of hypoglycemia associated with the deterioration of patients' conditions cannot be excluded. Studies with larger samples may help to clarify this issue.

Ketoacidosis generally occurs in children aged $<5$ years with type I diabetes and low levels of effective insulin action $(29,33)$. In the present study, no evidence of this condition was indicated, even in patients who received no insulin therapy. Due to its transient nature, stress hyperglycemia may not cause ketoacidosis in non-diabetic patients (4).

Insulin therapy revealed no benefit in terms of the length of hospitalization or risk of organ dysfunction or fatality, and thus was not associated with improved clinical outcomes in critically ill infants with stress hyperglycemia. Even without insulin therapy, the blood glucose level may spontaneously return to normal with no associated risk. However, further prospective randomized controlled trials are required to confirm the findings of the present study.

The mechanisms why insulin therapy exhibited no benefit in pediatric patients with stress hyperglycemia in the present study remain clear. Because this is a retrospective study, all patients lacked data regarding insulin, c-peptide response and inflammatory factors. Future prospective randomized controlled trials will explore these mechanisms.

\section{Acknowledgements}

Not applicable.

\section{Funding}

The study was supported by the Department of Science and Technology of Guangdong Province in 2011 (grant no. 2011B031800134).

\section{Availability of data and materials}

The datasets used and/or analyzed during the current study are available from the corresponding author on reasonable request.

\section{Authors' contributions}

FW and YZ conceived and designed the experiments of the current study. YZ, CL, MD and JfZ performed the experiments. FW and JfZ analyzed the data.JpZcontributed reagents/materials/ analysis tools. FW and $\mathrm{CL}$ wrote the manuscript.

\section{Ethics approval and consent to participate}

The current study was approved by the ethics committee of the Shunde Women and Children's Healthcare Hospital (Foshan, China).

\section{Patient consent for publication}

All parents and guardians of the children enrolled in the current study provided written informed consent.

\section{Competing interests}

The authors declare that they have no competing interests.

\section{References}

1. Ali Abdelhamid Y, Kar P, Finnis ME, Phillips LK, Plummer MP, Shaw JE, Horowitz M and Deane AM: Stress hyperglycaemia in critically ill patients and the subsequent risk of diabetes: A systematic review and meta-analysis. Crit Care 20: 301, 2016

2. Sanches LC, Pontes Azevedo LC, Salomao R, Noguti MA, Brunialti M, Lourenco DM and Machado FR: Association between early glycemic control and improvements in markers of coagulation and fibrinolysis in patients with septic shock-induced stress hyperglycemia. J Crit Care 29: 884.e1-e6, 2014.

3. Clowes GH Jr, Martin H, Walji S, Hirsch E, Gazitua R and Goodfellow R: Blood insulin responses to blood glucose levels in high output sepsis and spetic shock. Am J Surg 135: 577-583, 1978 .

4. NICE-SUGAR Study Investigators; Finfer S, Chittock DR, Su SY, Blair D, Foster D, Dhingra V, Bellomo R, Cook D, Dodek P, et al: Intensive versus conventional glucose control in critically ill patients. N Engl J Med 360: 1283-1297, 2009.

5. Cappi SB, Noritomi DT, Velasco IT, Curi R, Loureiro TC and Soriano FG: Dyslipidemia: A prospective controlled randomized trial of intensive glycemic control in sepsis. Intensive Care Med 38: 634-641, 2012.

6. Robinson LE and van Soeren MH: Insulin resistance and hyperglycemia in critical illness: role of insulin in glycemic control. AACN Clin Issues 15: 45-62, 2004.

7. Agus MS, Hirshberg E, Srinivasan V, Faustino EV, Luckett PM Curley MA, Alexander J, Asaro LA, Coughlin-Wells K, Duva D, et al: Design and rationale of heart and lung failure-pediatric INsulin titration trial (HALF-PINT): A randomized clinical trial of tight glycemic control in hyperglycemic critically ill children. Contemp Clin Trials 53: 178-187, 2017.

8. Yamada T, Shojima N, Hara K, Noma H, Yamauchi T and Kadowaki T: Glycemic control, mortality, secondary infection, and hypoglycemia in critically ill pediatric patients: A systematic review and network meta-analysis of randomized controlled trials. Intensive Care Med 43: 1427-1429, 2017.

9. Van den Berghe G, Wouters PJ, Bouillon R, Weekers F, Verwaest C, Schetz M, Vlasselaers D, Ferdinande P and Lauwers P: Outcome benefit of intensive insulin therapy in the critically ill: insulin dose versus glycemic control. Crit Care Med 31: 359-366, 2003.

10. van Steen SC, Rijkenberg S, Limpens J, van der Voort PH, Hermanides J and DeVries JH: The clinical benefits and accuracy of continuous glucose monitoring systems in critically Ill patients-a systematic scoping review. Sensors (Basel) 17: pii: E146, 2017.

11. Perez-Calatayud AA, Guillen-Vidana A, Fraire-Felix IS, Anica-Malagon ED, Briones Garduno JC and Carrillo-Esper R: Metabolic control in the critically ill patient an update: Hyperglycemia, glucose variability hypoglycemia and relative hypoglycemia. Cir Cir 85: 93-100, 2017 (In Spanish).

12. Kaminska H, Wieczorek P, Skala-Zamorowska E, Deja G and Jarosz-Chobot P: Dysglycemia in critically ill children. Pediatr Endocrinol Diabetes Metab 22: 21-25, 2016.

13. Plummer MP, Finnis ME, Phillips LK, Kar P, Bihari S, Biradar V, Moodie S, Horowitz M, Shaw JE and Deane AM: Stress induced hyperglycemia and the subsequent risk of type 2 diabetes in survivors of critical Illness. PLoS One 11: e0165923, 2016.

14. Tran NK, Godwin ZR, Steele AN, Wolf SE and Palmieri TL: Clinical impact of accurate Point-of-care glucose monitoring for tight glycemic control in severely burned children. Pediatr Crit Care Med 17: e406-e412, 2016.

15. Pham TN, Warren AJ, Phan HH, Molitor F, Greenhalgh DG and Palmieri TL: Impact of tight glycemic control in severely burned children. J Trauma 59: 1148-1154, 2005.

16. Vlasselaers D, Mesotten D, Langouche L, Vanhorebeek I, van den Heuvel I, Milants I, Wouters P, Wouters P, Meyns B, Bjerre M, et al: Tight glycemic control protects the myocardium and reduces inflammation in neonatal heart surgery. Ann Thorac Surg 90: 22-29, 2010.

17. Day KM, Haub N, Betts H and Inwald DP: Hyperglycemia is associated with morbidity in critically ill children with meningococcal sepsis. Pediatr Crit Care Med 9: 636-640, 2008. 
18. Vlasselaers D: Blood glucose control in the intensive care unit: Discrepancy between belief and practice. Crit Care 14: 145, 2010.

19. Agus MS: Tight glycemic control in children-is the target in sight? N Engl J Med 370: 168-169, 2014.

20. Yatabe T, Inoue S, Sakaguchi M and Egi M: The optimal target for acute glycemic control in critically ill patients: A network meta-analysis. Intensive Care Med 43: 16-28, 2017.

21. Asencio $\mathrm{Y}$, Lamy $\mathrm{F}$ and Paut $\mathrm{O}$ : Is it necessary to obtain a tight glycemic control in critically ill children? Ann Fr Anesth Reanim 29: 570-572, 2010 (In French).

22. Clement S, Braithwaite SS, Magee MF, Ahmann A, Smith EP, Schafer RG and Hirsch IB: Management of diabetes and hyperglycemia in hospitals. Diabetes Care 27: 553-591, 2004.

23. Singer M, Deutschman CS, Seymour CW, Shankar-Hari M, Annane D, Bauer M, Bellomo R, Bernard GR, Chiche JD, Coopersmith CM, et al: The third international consensus definitions for sepsis and septic shock (Sepsis-3). JAMA 315: 801-810, 2016.

24. Kar P, Plummer MP, Bellomo R, Jenkins AJ, Januszewski AS, Chapman MJ, Jones KL, Horowitz M and Deane AM: Liberal glycemic control in critically Ill patients with type 2 diabetes: An exploratory study. Crit Care Med 44: 1695-1703, 2016.

25. Zucchini S, Scaramuzza AE, Bonfanti R, Buono P, Cardella F, Cauvin V, Cherubini V, Chiari G, d'Annunzio G, Frongia AP, et al: A multicenter retrospective survey regarding diabetic ketoacidosis management in Italian children with type 1 diabetes. J Diabetes Res 2016: 5719470, 2016.

26. Abstracts for the $42 \mathrm{nd}$ annual meeting of the international society for pediatric and adolescent diabetes (ISPAD), 26-29 October 2016, Valencia, Spain. Pediatr Diabetes 17 (Suppl 24): S5-S176, 2016.
27. Joffe A, Anton N, Lequier L, Vandermeer B, Tjosvold L, Larsen B and Hartling L: Nutritional support for critically ill children. Cochrane Database Syst Rev 2209: CD005144, 2009.

28. Marik PE and Raghavan M: Stress-hyperglycemia, insulin and immunomodulation in sepsis. Intensive Care Med 30: 748-756, 2004.

29. Van den Berghe G, Wouters P, Weekers F, Verwaest C, Bruyninckx F, Schetz M, Vlasselaers D, Ferdinande P, Lauwers P and Bouillon R: Intensive insulin therapy in critically ill patients. N Engl J Med 345: 1359-1367, 2001.

30. Aberegg SK: Intensive insulin therapy in the medical ICU. N Engl J Med 354: 2069-2071, 2006.

31. Luethi N, Cioccari L, Crisman M, Bellomo R, Eastwood GM and Martensson J: Prevalence of ketosis, ketonuria, and ketoacidosis during liberal glycemic control in critically ill patients with diabetes: An observational study. Crit Care 20: 297, 2016.

32. Branco RG, Xavier L, Garcia PC, Piva JP, Fiori HH, Baldisserotto M, Fiori RM and Tasker RC: Prospective operationalization and feasibility of a glycemic control protocol in critically ill children. Pediatr Crit Care Med 12: 265-270, 2011.

33. Szypowska A, Ramotowska A, Grzechnik-Gryziak M, Szypowski W, Pasierb A and Piechowiak K: High frequency of diabetic ketoacidosis in children with newly diagnosed type 1 diabetes. J Diabetes Res 2016: 9582793, 2016. 